\title{
Bartonella henselae bacteremia in a mother and son potentially associated with tick exposure
}

\author{
Ricardo G Maggi ${ }^{1,3^{*}}$, Marna Ericson², Patricia E Mascarelli ${ }^{1}$, Julie M Bradley ${ }^{1}$ and Edward B Breitschwerdt
}

\begin{abstract}
Background: Bartonella henselae is a zoonotic, alpha Proteobacterium, historically associated with cat scratch disease (CSD), but more recently associated with persistent bacteremia, fever of unknown origin, arthritic and neurological disorders, and bacillary angiomatosis, and peliosis hepatis in immunocompromised patients. A family from the Netherlands contacted our laboratory requesting to be included in a research study (NCSU-IRB\#1960), designed to characterize Bartonella spp. bacteremia in people with extensive arthropod or animal exposure. All four family members had been exposed to tick bites in Zeeland, southwestern Netherlands. The mother and son were exhibiting symptoms including fatigue, headaches, memory loss, disorientation, peripheral neuropathic pain, striae (son only), and loss of coordination, whereas the father and daughter were healthy.
\end{abstract}

Methods: Each family member was tested for serological evidence of Bartonella exposure using B. vinsonii subsp. berkhoffii genotypes I-III, B. henselae and B. koehlerae indirect fluorescent antibody assays and for bacteremia using the BAPGM enrichment blood culture platform.

Results: The mother was seroreactive to multiple Bartonella spp. antigens and bacteremia was confirmed by PCR amplification of $B$. henselae DNA from blood, and from a BAPGM blood agar plate subculture isolate. The son was not seroreactive to any Bartonella sp. antigen, but $B$. henselae DNA was amplified from several blood and serum samples, from BAPGM enrichment blood culture, and from a cutaneous striae biopsy. The father and daughter were seronegative to all Bartonella spp. antigens, and negative for Bartonella DNA amplification.

Conclusions: Historically, persistent B. henselae bacteremia was not thought to occur in immunocompetent humans. To our knowledge, this study provides preliminary evidence supporting the possibility of persistent B. henselae bacteremia in immunocompetent persons from Europe. Cat or flea contact was considered an unlikely source of transmission and the mother, a physician, reported that clinical symptoms developed following tick exposure. To our knowledge, this is the first time that a B. henselae organism has been visualized in and amplified from a striae lesion. As the tick bites occurred three years prior to documentation of $B$. henselae bacteremia, the mode of transmission could not be determined.

Keywords: Bartonella, BAPGM, Bacteremia, Striae, Neuropathy, Neurological disorder

\section{Background}

Due to complex nutritional requirements and slow dividing times, which necessitate a prolonged incubation period for successful isolation, members of the genus Bartonella are highly fastidious microorganisms that are difficult to document microbiologically in patient blood

\footnotetext{
* Correspondence: rgmaggi@ncsu.edu

'Intracellular Pathogens Research Laboratory, Center for Comparative

Medicine and Translational Research, College of Veterinary Medicine, North Carolina State University, Raleigh, NC, USA

${ }^{3}$ Galaxy Diagnostics Inc., Research Triangle Park, Durham, USA

Full list of author information is available at the end of the article
}

or tissue specimens [1]. Over the past decade, evolving evidence supports the fact that these bacteria can induce long-lasting intravascular infections in animals that serve as reservoir-adapted hosts, whereas, more recently a number of Bartonella sp. have been associated with persistent bacteremia in immunocompetent human patients experiencing a spectrum of symptoms and somewhat diverse disease pathologies [2,3]. On a comparative medical basis, Bartonella infection induces similar pathology in dogs, people, and other animals [3,4]. Infection with one or more Bartonella sp. has also been associated with

\section{Biomed Central}


fever of unknown origin [5-9], and arthritic and neurological disorders [10-12].

In an effort to overcome limitations associated with the molecular detection and isolation of Bartonella spp. from animals and immunocompetent human patients, our laboratory developed a novel diagnostic platform based on biochemical optimization of a modified insect-cell culture liquid medium (Bartonella alpha Proteobacteria Growth Medium or BAPGM) [13]. The BAPGM platform consists of PCR amplification of Bartonella DNA from the patient's extracted blood and serum samples before, and after BAPGM enrichment culture and from isolates, if obtained, following subculture of pre-enriched samples onto blood agar plates. Research utilization of this testing platform has facilitated the documentation of $B$. henselae bacteremia in patients from the Australia [14], England [14], and the United States [10-12,15]. In addition, utilization of the BAPGM enrichment blood culture platform has facilitated the isolation or molecular detection of other Bartonella spp. including Bartonella vinsonii subsp. berkhoffii genotypes I and II [10-12,15,16], Bartonella koehlerae [10,12,14,17], Candidatus Bartonella melophagi [18], and a novel Bartonella sp. related to Bartonella volans [19], from the blood of immunocompetent humans $[10,11,13]$. Standardized precautions are routinely used in our laboratory to avoid DNA contamination and negative controls are used in each step of the testing platform, including culture, DNA extraction and PCR negative controls. All conventional PCR amplicons are sequenced to confirm the Bartonella species and 16S-23S ITS strain type. In this study, four members of a family from the Netherlands were tested for serological, microbiological (isolation) or molecular (PCR amplification and DNA sequencing) evidence of Bartonella exposure or bacteremia, using five indirect fluorescent antibody assays and the Bartonella alpha Proteobacteria growth medium (BAPGM) enrichment culture platform, respectively. In addition, skin biopsies were obtained surgically from the son for BAPGM enrichment culture, histopathology, and laser confocal immunohistochemistry.

\section{Methods}

\section{Patients and samples}

While reviewing recently published literature relative to potential transmission of Bartonella species by ticks [20-24], the mother, a 58-year-old anesthesiologist from the Netherlands contacted one of the investigators in our laboratory (EBB) by email and requested BAPGM enrichment blood culture testing to determine if she and her son could have been infected with a Bartonella sp. following tick bites. It was ultimately decided that the family would be tested in conjunction with an ongoing research study designed to determine the prevalence of bacteremia in people with animal and arthropod exposure. This research study was reviewed and approved by the North Carolina State University Institutional Review Board (NCSU IRB\#1960) to assure conformity with all confidentiality and patient assurance laws in the United States. In July 2008, prior to the onset of illness in the mother and son, all four family members had experienced tick bites at the family vacation home in Zeeland, located in southwestern Netherlands, where they reported a large deer population. Tick attachments had also occurred during subsequent summer vacations. The family did not own a cat or dog, and all family members denied exposure to cats and cat fleas. During the three years prior to testing in the Intracellular Pathogens Research Laboratory (IPRL), the mother reported fatigue, headaches, memory loss, irritability, disorientation, chest pain, syncope (two episodes), fine tremors, shoulder pain, joint pain, loss of coordination, and peripheral neuropathic pain involving the arms. The son (an 18-year-old student) reported an illness of three-year duration, with symptoms including: fatigue, headaches, fine tremors, red conjunctivae, cervical lymphadenopathy, and striae involving both legs and the buttock. In the context of this manuscript, striae are irregular bands, stripes or lines in the skin. Between July 2009 and July 2011, both the mother and son underwent multiple diagnostic evaluations for infectious and non-infectious diseases. Both had been treated for a potential Borrelia sp. infection with multiple antibiotic combinations (azithromycin, cefuroxime, metronidazole, rifampin, tetracycyline) for at least 6 weeks duration, on several occasions. The historical response to antibiotics was inconsistent and difficult to assess, but in general, symptoms would diminish while receiving antibiotics and reoccur weeks to months after antibiotic administration ended. The last date in which the mother and son took antibiotics was May 24, 2011 and July 7, 2011, respectively. The father (64-year-old investment banker) and daughter (20-year-old medical student) were not symptomatic prior to or at the time of sample collection. As a physician, the mother decided that shipping samples from Europe to the United States might compromise sample integrity, thereby contributing to false negative test results. Therefore, after flying to North Carolina, the mother and son's blood samples were aseptically collected during the last week of July 2011, whereas the father and daughter's samples were collected the first week of August 2011. After the two week sample collection period, the family flew back to the Netherlands to await research testing results, which required months to complete. Three aseptically collected blood and serum samples were obtained during a one-week period from the mother, father, son and daughter. Three skin biopsy samples, which included a blue nevus located over the right deltoid, and a striae lesion $(0.4 \times 0.3 \mathrm{~cm}$, excised to a depth of $0.5 \mathrm{~cm})$ located on the left thigh, were surgically obtained from the son at a hospital in Raleigh, North Carolina, during the same time 
frame as blood samples were being collected. Blood, serum and skin biopsy samples were processed and tested in the IPRL, as described below. Histopathological examination of hematoxylin and eosin stained tissue sections was performed by the consulting human pathologist for the local hospital. Frozen tissues were sent to the Cutaneous Imaging Center, Department of Dermatology and Center for Drug Design, University of Minnesota to determine if Bartonella organisms could be visualized.

\section{Bartonella spp. IFA testing}

Antibody seroreactivity to $B$. vinsonii subsp. berkhoffii genotypes I, II and III, B. henselae (strain Houston I), and $B$. koehlerae were determined using previously described indirect fluorescent antibody tests $[10,11,25]$.

\section{BAPGM enrichment culture}

The BAPGM enrichment culture platform, which has been employed by several research laboratories [26-28] was used to assess for Bartonella sp. bacteremia. Briefly the procedure included inoculation of $2 \mathrm{ml}$ of blood and up to $2 \mathrm{ml}$ of serum collected the same day into a culture flask containing $10 \mathrm{ml}$ of BAPGM. Cultures were incubated for up to 14 days at $36^{\circ} \mathrm{C}$ with $5 \% \mathrm{CO}_{2}$ and $100 \%$ humidity with constant agitation. A milliliter of each enrichment culture sample was sub-inoculated onto blood agar plates (10\% rabbit blood, TSA II) at 7 and 14 days after incubation of the BAPGM flask for potential colony formation. For each patient sample tested using the BAPGM platform, an un-inoculated BAPGM culture was processed in an identical and simultaneous manner to monitor for potential laboratory contamination (quality assurance).

\section{DNA extraction, PCR amplification and DNA sequencing} Using established assays, PCR targeting the Bartonella 16S-23S intergenic spacer (ITS) region was used to amplify Bartonella spp. DNA from extracted blood, serum, skin biopsies, BAPGM enrichment cultures and isolates [10]. All PCR products obtained after amplification of extracted DNA from blood, serum and tissue samples, after BAPGM enrichment, and from agar plate colonies were sequenced directly or after cloning. Bacterial species and strain were defined by comparing DNA sequence similarities with other sequenced bacteria deposited in the GenBank database using the Basic Local Alignment Search Tool (Blast version 2.0).

\section{Bartonella confocal microscopy}

An excised skin biopsy sample from the son (striae lesion) was drop-fixed in formalin and stored at room temperature. As a negative control, a scalp skin 4-mm punch biopsy was drop-fixed in Zamboni's fixative $(0.03 \%$ (w/v) picric acid and $2 \%(\mathrm{w} / \mathrm{v})$ paraformaldehyde) for $48 \mathrm{~h}$ at $4{ }^{\circ} \mathrm{C}$ and then transferred to a $20 \%$ sucrose solution with $0.05 \%$ sodium azide in PBS for storage. Processing and multi-staining of tissues specimens was performed according to a previously published procedure $[29,30]$. Vertical sections, 60 -microns thick, were mounted in and cut on a cryostat. Floating sections were then incubated with primary antibodies to Collagen Type IV at a 1:200 dilution (Southern Biotech, 1340-01), donkey anti-goat Cy3 at 1:500 dilution (Jackson Immunoresearch, West Grove, PA), and a mouse antibody to Bartonella henselae at a 1:100 dilution (Abcam, ab704250) plus donkey anti-mouse Cy5 at a 1:500 dilution (Jackson Immunoresearch). Washed samples were subsequently fixed to cover slips in agar, dehydrated in ethanol, cleared with methyl salicylate, and mounted in DEPEX (Electron Microscopy Sciences, Hatfield, PA).

\section{Results}

The son was not seroreactive to $B$. henselae, B. koehlerae or $B$. vinsonii subsp. berkhoffii genotype I, II or III antigens by IFA testing (Table 1). However, $B$. henselae (16S-23S SA2 strain type) DNA was amplified and successfully sequenced from his blood, serum, a BAPGM enrichment blood culture, and from the striae biopsy sample (Table 2). Bartonella spp. DNA was not amplified from the biopsy of the son's blue nevus. In contrast to her son, the mother was seroreactive to $B$. henselae (at an endpoint titer of 1:64), B. koehlerae (1:64), and B. vinsonii subsp. berkhoffii genotypes II and III antigens (both 1:64), but was not seroreactive to $B$. vinsonii subsp. berkhoffii genotype I. Bartonella henselae SA2 bacteremia was confirmed in the mother by PCR amplification and DNA sequencing (460/460 bp homology with GenBank AF369529) of 16S23S ITS PCR amplicons from an extracted blood sample and from colonies obtained on blood agar plates following BAPGM enrichment $[10,11,18]$ from the same collection date. Isolation of $B$. henselae from the mother's blood and

Table 1 Indirect fluorescent serum antibody results for the four family members

\begin{tabular}{ccccccc}
\hline Patient & Collection date & $\boldsymbol{B v b}$ TI & $\boldsymbol{B v b}$ TII & $\boldsymbol{B v b}$ TIII & $\boldsymbol{B h}$ & $\boldsymbol{B k}$ \\
\hline \multirow{4}{*}{ Son } & $7 / 25 / 2011$ & $<16$ & $<16$ & $<16$ & $<16$ & $<16$ \\
\cline { 2 - 7 } & $7 / 27 / 2011$ & $<16$ & $<16$ & $<16$ & $<16$ & $<16$ \\
\cline { 2 - 7 } & $7 / 29 / 2011$ & $<16$ & $<16$ & $<16$ & $<16$ & $<16$ \\
\hline \multirow{4}{*}{ Mother } & $7 / 25 / 2011$ & $<16$ & 64 & $<16$ & 64 & 64 \\
\cline { 2 - 7 } & $7 / 27 / 2011$ & $<16$ & 64 & 64 & 64 & 64 \\
\cline { 2 - 7 } & $7 / 29 / 2011$ & $<16$ & 64 & $<16$ & 64 & 64 \\
\hline \multirow{4}{*}{ Daughter } & $8 / 1 / 2011$ & $<16$ & $<16$ & $<16$ & 32 & $<16$ \\
\cline { 2 - 7 } & $8 / 2 / 2011$ & $<16$ & $<16$ & $<16$ & 32 & $<16$ \\
\cline { 2 - 7 } & $8 / 5 / 2011$ & $<16$ & $<16$ & $<16$ & 32 & $<16$ \\
\hline \multirow{3}{*}{ Father } & $8 / 1 / 2011$ & $<16$ & $<16$ & $<16$ & 32 & $<16$ \\
\cline { 2 - 7 } & $8 / 2 / 2011$ & $<16$ & $<16$ & $<16$ & 32 & $<16$ \\
\cline { 2 - 7 } & $8 / 5 / 2011$ & $<16$ & $<16$ & $<16$ & 32 & $<16$ \\
\hline
\end{tabular}

Bh: $B$. henselae; Bk: $B$. koehlerae; Bvb: $B$. vinsonii subsp. berkhoffii.

$\mathrm{TI}$, III, TIII denote $B$. vinsonii subsp. berkhoffii genotypes I, II and III, respectively. 
Table 2 Bartonella spp. blood, serum, BAPGM enrichment blood culture, subculture and tissue PCR testing results for the four family members

\begin{tabular}{|c|c|c|c|c|c|}
\hline Patient & Sample type & Collection date & PCR sample & PCR culture & PCR isolate \\
\hline \multirow{9}{*}{ Son } & Serum & 7/29/2011 & Neg & \multirow[t]{2}{*}{ Neg } & \multirow[t]{2}{*}{ Neg } \\
\hline & Blood & 7/29/2011 & Neg & & \\
\hline & Blue nevus & $7 / 25 / 2011$ & $\mathrm{Neg}$ & Neg & Neg \\
\hline & Normal skin & $7 / 25 / 2011$ & Neg & Neg & Neg \\
\hline & Striae & $7 / 25 / 2011$ & BhSA2 & Neg & Neg \\
\hline & Serum & $7 / 25 / 2011$ & BhSA2 & \multirow[t]{2}{*}{ Neg } & \multirow[t]{2}{*}{ Neg } \\
\hline & Blood & $7 / 25 / 2011$ & BhSA2 & & \\
\hline & Serum & 7/27/2011 & BhSA2 & \multirow[t]{2}{*}{ Bh SA2 } & \multirow[t]{2}{*}{ Neg } \\
\hline & Blood & 7/27/2011 & BhSA2 & & \\
\hline \multirow{6}{*}{ Mother } & Serum & $7 / 25 / 2011$ & Neg & \multirow[t]{2}{*}{ Neg } & \multirow[t]{2}{*}{ Neg } \\
\hline & Blood & $7 / 25 / 2011$ & Neg & & \\
\hline & Serum & 7/27/2011 & Neg & \multirow[t]{2}{*}{ Neg } & \multirow[t]{2}{*}{ Bh SA2 } \\
\hline & Blood & $7 / 27 / 2011$ & BhSA2 & & \\
\hline & Serum & 7/29/2011 & Neg & \multirow[t]{2}{*}{ Neg } & \multirow[t]{2}{*}{ Neg } \\
\hline & Blood & $7 / 29 / 2011$ & Neg & & \\
\hline \multirow{6}{*}{ Daughter } & Serum & 8/1/2011 & Neg & \multirow[t]{2}{*}{ Neg } & \multirow[t]{2}{*}{ Neg } \\
\hline & Blood & 8/1/2011 & Neg & & \\
\hline & Serum & $8 / 2 / 2011$ & Neg & \multirow[t]{2}{*}{ Neg } & \multirow[t]{2}{*}{ Neg } \\
\hline & Blood & 8/2/2011 & Neg & & \\
\hline & Serum & $8 / 5 / 2011$ & Neg & \multirow[t]{2}{*}{ Neg } & \multirow[t]{2}{*}{ Neg } \\
\hline & Blood & $8 / 5 / 2011$ & Neg & & \\
\hline \multirow{6}{*}{ Father } & Serum & $8 / 1 / 2011$ & Neg & \multirow[t]{2}{*}{ Neg } & \multirow[t]{2}{*}{$\mathrm{Neg}$} \\
\hline & Blood & $8 / 1 / 2011$ & Neg & & \\
\hline & Serum & $8 / 2 / 2011$ & Neg & \multirow[t]{2}{*}{ Neg } & \multirow[t]{2}{*}{ Neg } \\
\hline & Blood & $8 / 2 / 2011$ & Neg & & \\
\hline & Serum & $8 / 5 / 2011$ & Neg & \multirow[t]{2}{*}{ Neg } & \multirow[t]{2}{*}{ Neg } \\
\hline & Blood & $8 / 5 / 2011$ & Neg & & \\
\hline
\end{tabular}

amplification of $B$. henselae DNA after enrichment blood culture from the son supported active infection with viable intravascular bacteria. The father and daughter were not seroreactive to the Bartonella spp. test antigens used in this study and $B$. henselae DNA was not amplified from any of their blood, serum or BAPGM enrichment blood cultures. As detailed in previous studies [10,11], Bartonella DNA was not amplified from any of the simultaneously processed BAPGM negative culture controls (results not shown).

The gross appearance of the son's striae are depicted in Figure 1A and 1B. Histopathology of the right deltoid skin lesion contained features of a blue nevus. The striae lesional biopsy from the left thigh contained minimal nonspecific superficial perivascular chronic inflammation (Figure $1 \mathrm{C}$ and $1 \mathrm{D}$ ). Immunostaining of the striae tissue from the son's skin biopsy revealed $B$. henselae immuno-positive staining within the dermis and by confocal microscopy imaging, the bacteria were external to vascular tissue (Figure 2).
After these results were obtained, the son elected to not be treated with additional antibiotics. During 2012 he remained mostly healthy, and passed Propedeuse exam Cum Laude. The striae regressed spontaneously leaving slight, colorless and painless marks. Conjunctivitis and the fine motor tremor have persisted. Psoriasis was diagnosed in 2012 for which he is being treated with vitamin supplementation and immune stimulants. The mother also did not seek treatment for $B$. henselae bacteremia until several months after test results became available, when she developed severe myalgia, tendinitis involving several joints and paresthesias. She was treated with intraveneous ceftriaxone 4 gram twice a week for six months. After three months of antibiotic therapy, Bartonella serology was reported as positive (IFA titer 1:32-normal < 32). During the final two months of antibiotic therapy, rifampin, hyperthermic therapy every day (sauna) and hyperbaric oxygen therapy by mask in a high-pressure cabin 2.4 bar, for 75 minutes each day were administered for 45 days. None of these therapies 


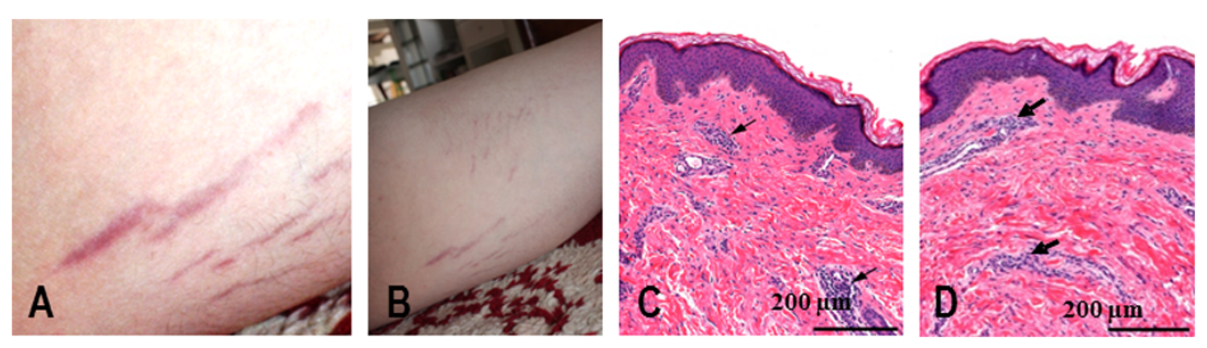

Figure 1 Gross appearance of striae located on the thigh of the son (A \& B, photographs provided by the family) and the hematoxylin/eosin stained striae tissue biopsy (C \& D) illustrating (arrows) minimal nonspecific superficial perivascular chronic inflammation.

decreased the woman's symptoms. As of March 2013, the father and daughter have remained healthy.

\section{Discussion}

In this study, B. henselae bacteremia was confirmed in the two symptomatic family members, but not in the two historically healthy family members. Although the symptoms that developed in 2008 as reported by the physician and her son were similar to questionnaire respondent symptoms reported by other patients with $B$. henselae bacteremia $[10,11]$, it is not possible to determine whether the symptoms in these two family members were due in part or total to infection with this organism. Unless re-infection was occurring, prior efforts to eliminate $B$. henselae with antibiotics were not successful, further supporting the possibility that antibiotic treatment failure can occur in a subset of $B$. henselae bacteremic patients $[14,31]$. As our research group was not involved in patient management decisions prior to or after $B$. henselae bacteremia was confirmed, the purpose of this report was to provide evidence supporting $B$. henselae bacteremia in two immmunocompetent individuals from Europe, who believed that tick transmission was the most likely source of their infections. During the previous three years, all four family members reported tick bites while vacationing in southwestern Holland and all denied exposure to cats. As $B$. henselae DNA was successfully amplified and sequenced from one of the son's BAPGM enrichment blood cultures and from a subculture isolate obtained from the mother's blood, bacteremia (viable bacteria) was confirmed in both individuals despite prior administration of antibiotics. Only one of three blood culture sample sets from the mother and the son resulted in enrichment culture or isolation evidence to support the presence of bacteremia, which is consistent with prior experience with the BAPGM platform when testing sequentially-obtained blood samples from sick human patients $[10,11,16,17,19,32]$. Presumably, failure to document infection in two of the three sample sets is potentially due to a relapsing pattern of bacteremia in humans [33-36], as has been reported in experimentallyinfected cats $[37,38]$ and rodents $[33,39,40]$. Due to
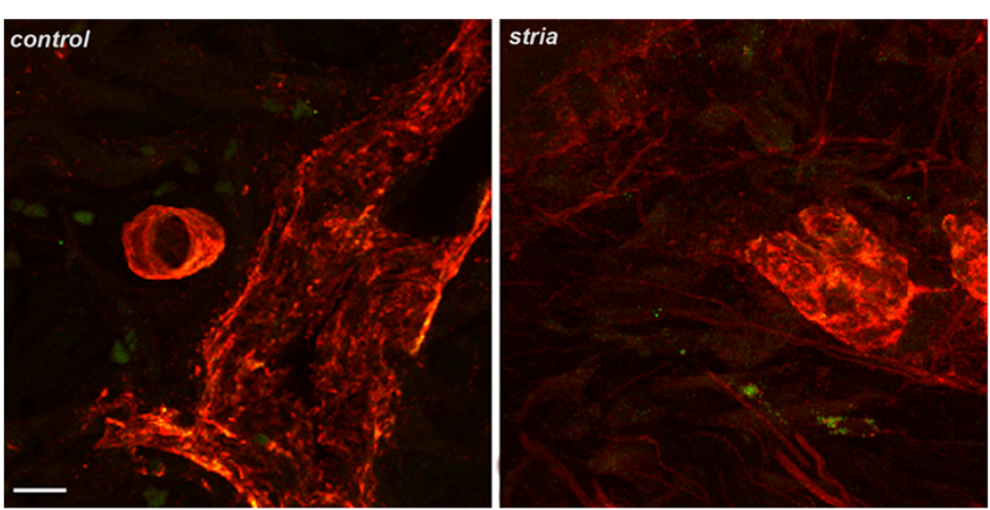

Figure 2 Photomicrographs captured using laser scanning confocal microscopy demonstrating immunoreactive $B$. henselae organisms in the striae skin biopsy obtained from the son's thigh (right panel, small green particles). Left panel is scalp skin from a non-infected subject also immunostained with $B$. henselae antibody. No bacteria were visualized in control sections, although relatively large auto fluorescent red blood cells are partially visible (pseudo-colored green). Both samples also stained with collagen IV to highlight immunoreactive vascular tissue (pseudo-colored red). Note bacteria within skin appear external to vascular tissues. Images are projections of 31, 0.48-micron thick optical sections, total thickness 15 microns. Scale bar $=10$ microns. 
diagnostic limitations associated with serology, direct blood plating methods, and PCR following DNA extraction directly from patient samples, our research group developed and have used a combined method that incorporates PCR from extracted blood, serum and BAPGM enrichment blood culture $[10,11,17]$. This study further supports the enhanced diagnostic sensitivity of the BAPGM enrichment blood culture platform for documentation of Bartonella spp. bacteremia in immunocompetent patients, and provides additional support for the need to test three sample sets obtained during a one week collection period [32].

In addition to documentation of bacteremia, immunohistochemical confocal microscopy was used to visualize $B$. henselae organisms in the son's striae tissue biopsy. This observation provides preliminary evidence to support a potential association between $B$. henselae infection and striae. Although lay publications have frequently reported [41,42] that striae are caused by Bartonella sp. infections, to our knowledge there are no scientific publications that have investigated, reported, or confirmed this possibility. Clearly, additional immunohistochemical studies of striae would be of interest to determine if persistent Bartonella sp. bacteremia could contribute to the development of these skin lesions in human patients.

As is true throughout much of the world, $B$. henselae infection in immunocompetent people has been reported previously in the Netherlands in association with the diagnosis of typical or atypical cases of cat scratch disease (CSD) $[43,44]$. Cats, infected with $B$. henselae by cat fleas (Ctenocephalides felis), develop a bacteremia that can persist for years [37,45-49]. The term cat scratch disease is clearly of historical medical importance, but continued use of the term as a sole reference to $B$. henselae or other Bartonella sp. infections is potentially detrimental for patient diagnosis and patient management decisions. Briefly, $B$. henselae, the acknowledged cause of CSD, has also been documented (by PCR or isolation) in dogs [13,25,50-54], dolphins [55,56], feral swine [57], horses [58-60], and Beluga whales [61]. In North America, B. henselae is the most frequent Bartonella species isolated from bacteremic sick dogs [54] and people [10,11,62]. In a recent report of a patient with neuroretinitis in Australia, a well-documented ocular pathology induced by $B$. henselae, bartonellosis was diagnosed following the bite (sting) of a bull ant (genus Myrmecia) [21]. Those authors also advocated for medical use of the more inclusive term bartonellosis. Thus, because of alternative vectors, numerous accidental or reservoir hosts, and the seemingly broad spectrum of disease manifestations, referring to all $B$. henselae infections as CSD is a contradiction in fact, and the use of the more globally applicable term such as bartonellosis is suggested. In addition, CSD is considered a self-limiting infection for which antibiotic therapy is not recommended, whereas more recent evidence indicates that antibiotic elimination of $B$. henselae bacteremia can be extremely challenging, and potentially difficult to achieve [19,31]. Interestingly, molecular differences among $B$. henselae isolates based on $16 \mathrm{~S}$ rDNA sequences and multiple-locus variable number tandem repeat analysis (MLVA), have documented the presence of two different $B$. henselae genotypes, one more frequently observed in association with human infections (genotype I), and the second (genotype II) most often isolated from bacteremic cats, suggesting that genotype II isolates may be minimally or nonpathogenic for humans (CSD) as compared with a more pathogenic and zoonotic genotype I $[63,64]$.

In recent years, a substantial number of European studies have reported the presence of $B$. henselae DNA in ticks, including I. ricinus [24,65-76], suggesting that ticks may act as an important ecological reservoir for this Bartonella species. In addition, several recent publications have provided indirect [22,23] or experimental vector competence evidence [24] to support transmission of Bartonella spp. (including B. henselae, B. birtlesii, and $B$. vinsonii subsp. berkhoffii) by ticks (including I. ricinus) [22-24]. Two previous studies have not documented Bartonella spp. DNA in ticks from the Netherlands $[46,77]$, where this family experienced tick exposures. Although not reported specifically in the results, $B$. henselae SA2 strain DNA was amplified and sequenced from two $I$. ricinus ticks from Klasdorf, Brandenburg, Germany, by targeting the 16S-23S rRNA intergenic spacer region [73] (Kempf VA, Maggi RG, unpublished data). The DNA sequences derived from these two ticks were identical to the $B$. henselae DNA sequences obtained from the two bacteremic people in this report. Interestingly, the remaining eight ticks that were sequenced as part of that study to confirm the Bartonella species and strain type contained a B. henselae 16S-23S Houston 1 DNA and were collected in southern Germany, France and Portugal, suggesting the possibility of $B$. henselae strain variation among ticks. It is also important to consider the tick life stage, as in that study the odds of detecting $B$. henselae DNA was 14 fold higher in nymphal ticks as compared to adult ticks [73]. In addition, differences in PCR sensitivity among studies and differences in Bartonella sp. gene targets used to test tick DNA extractions can contribute to divergent findings among laboratories, when testing ticks from the same location. Most previous studies designed to detect and identify Bartonella species in I. ricinus ticks from Europe have targeted the citrate synthase $(g l t A)$ and $16 \mathrm{~S}$ rRNA genes. Unfortunately, these genes have very limited genetic variability and therefore are not optimal to differentiate among $B$. henselae strains. Clearly the role of ticks as potential vectors for transmission of Bartonella sp. to animals and humans deserves additional research consideration. 


\section{Conclusion}

Although $B$. henselae infection was documented by PCR amplification and DNA sequencing in both of the sick members of this family, there may or may not be a causal relationship between the bacteria and the reported symptoms. Bartonella serology was supportive of $B$. henselae infection in the mother, but not in the son, further supporting reports of seronegative Bartonella sp. bacteremia in human patients $[10,11,78,79]$. Also, despite improvements in PCR sensitivity, immunohistochemical methods are useful to facilitate the visualization of Bartonella species in patient tissue specimens. Finally, as ticks removed from the patients were not saved for PCR testing, it is not clear whether infection with $B$. henselae was acquired by tick bites or by another mode of transmission.

\section{Consent}

Written informed consent was obtained from the patients for publication of this report and any accompanying images.

\section{Abbreviations}

ITS: Intergenic spacer; BAPGM: Bartonella alpha proteobacteria growth medium; IPRL: Intracellular pathogens research laboratory.

\section{Competing interests}

In conjunction with Dr. Sushama Sontakke and North Carolina State University, Dr. Breitschwerdt holds U.S. Patent No. 7,115,385; Media and Methods for cultivation of microorganisms, which was issued October 3 , 2006. He is the chief scientific officer for Galaxy Diagnostics, a company that provides diagnostic testing for the detection of Bartonella species infection in animals and human patients. Dr. Ricardo Maggi has led research efforts to optimize the BAPGM platform and is the Scientific Technical Advisor for Galaxy Diagnostics. All other authors have no potential conflicts.

\section{Authors' contributions}

RM and PM performed the BAPGM enrichment blood culture and PCR testing of the patient samples, performed DNA sequencing and alignments, and generated the first draft of the manuscript. ME performed the immunohistochemistry and confocal microscopy. JB assisted in sample acquisition and serological testing. EB coordinated various aspects of the investigation and helped to draft the final manuscript. All authors read and approved the manuscript.

\section{Acknowledgements}

The authors thank Dr. YD Podnos for obtaining the surgical biopsies and Dr. TR Carter for histopathological examination of the tissue biopsies and the family for flying to North Carolina to facilitate sample collection and timely submission to our laboratory for testing purposes. We also thank Barbara Hegarty and Tonya Lee for editorial assistance.

\section{Author details}

${ }^{1}$ Intracellular Pathogens Research Laboratory, Center for Comparative Medicine and Translational Research, College of Veterinary Medicine, North Carolina State University, Raleigh, NC, USA. ${ }^{2}$ Cutaneous Imaging Center, Department of Dermatology and Center for Drug Design, University of Minnesota, Minnesota, USA. ${ }^{3}$ Galaxy Diagnostics Inc., Research Triangle Park, Durham, USA.

Received: 14 March 2013 Accepted: 21 March 2013 Published: 15 April 2013

\section{References}

1. Maggi R: Bartonella. In Manual of Clinical Microbiology, Volume 2. 10th edition. Edited by Versalovic J. Washington: ASM; 2011.
2. Breitschwerdt EB, Maggi RG, Chomel BB, Lappin MR: Bartonellosis: an emerging infectious disease of zoonotic importance to animals and human beings. J Vet Emerg Crit Care (San Antonio) 2010, 20(1):8-30.

3. Beerlage C, Varanat M, Linder K, Maggi RG, Cooley J, Kempf VA, Breitschwerdt EB: Bartonella vinsonii subsp. berkhoffii and Bartonella henselae as potential causes of proliferative vascular diseases in animals. Med Microbiol Immunol 2012, 201(3):319-326.

4. Breitschwerdt EB, Maggi RG: Comparative medical features of canine and human bartonellosis. Clin Microbiol Infect 2009, 15(Suppl 2):106-107.

5. Zenone T: Systemic Bartonella henselae infection in immunocompetent adult presenting as fever of unknown origin. Case Rep Med 2011, 2011:183937.

6. Lin JW, Chen CM, Chang CC: Unknown fever and back pain caused by Bartonella henselae in a veterinarian after a needle puncture: a case report and literature review. Vector Borne Zoonotic Dis 2011, 11(5):589-591.

7. Boggs SR, Fisher RG: Bone pain and fever in an adolescent and his sibling. Cat scratch disease (CSD). Pediatr Infect Dis J 2011, 30(1):89. 93-84.

8. Myint KS, Gibbons RV, Iverson J, Shrestha SK, Pavlin JA, Mongkolsirichaikul D, Kosoy MY: Serological response to Bartonella species in febrile patients from Nepal. Trans R Soc Trop Med Hyg 2011, 105(12):740-742.

9. Bhengsri S, Baggett HC, Peruski LF Jr, Morway C, Bai Y, Fisk TL, Sitdhirasdr A, Maloney SA, Dowell SF, Kosoy M: Bartonella spp. infections, Thailand. Emerg Infect Dis 2010, 16(4):743-745.

10. Maggi RG, Mozayeni BR, Pultorak EL, Hegarty BC, Bradley JM, Breitschwerdt EB, Correa M: Bartonella spp. bacteremia and rheumatic symptoms in patients from Lyme disease-endemic region. Emerg Infect Dis 2012, 18(5):783-791.

11. Maggi RG, Mascarelli PE, Pultorak EL, Hegarty BC, Bradley JM, Mozayeni BR, Breitschwerdt EB: Bartonella spp. bacteremia in high-risk immunocompetent patients. Diagn Microbiol Infect Dis 2011, 71(4):430-437.

12. Breitschwerdt EB, Mascarelli PE, Schweickert LA, Maggi RG, Hegarty BC, Bradley JM, Woods CW: Hallucinations, sensory neuropathy, and peripheral visual deficits in a young woman infected with Bartonella koehlerae. J Clin Microbiol 2011, 49(9):3415-3417.

13. Duncan AW, Maggi RG, Breitschwerdt EB: A combined approach for the enhanced detection and isolation of Bartonella species in dog blood samples: pre-enrichment liquid culture followed by PCR and subculture onto agar plates. J Microbiol Methods 2007, 69(2):273-281.

14. Mascarelli PE, Iredell JR, Maggi RG, Weinberg G, Breitschwerdt EB: Bartonella species bacteremia in two patients with epithelioid hemangioendothelioma. J Clin Microbiol 2011, 49(11):4006-4012.

15. Breitschwerdt EB, Maggi RG, Duncan AW, Nicholson WL, Hegarty BC, Woods CW: Bartonella species in blood of immunocompetent persons with animal and arthropod contact. Emerg Infect Dis 2007, 13(6):938-941.

16. Breitschwerdt EB, Maggi RG, Lantos PM, Woods CW, Hegarty BC, Bradley JM: Bartonella vinsonii subsp. berkhoffii and Bartonella henselae bacteremia in a father and daughter with neurological disease. Parasit Vectors 2010, 3(1):29.

17. Breitschwerdt EB, Maggi RG, Mozayeni BR, Hegarty BC, Bradley JM, Mascarelli PE: PCR amplification of Bartonella koehlerae from human blood and enrichment blood cultures. Parasit Vectors 2010, 3(1):76.

18. Maggi RG, Kosoy M, Mintzer M, Breitschwerdt EB: Isolation of Candidatus Bartonella melophagi from human blood. Emerg Infect Dis 2009, 15(1):66-68.

19. Breitschwerdt EB, Maggi RG, Cadenas MB, de Paiva Diniz PP: A groundhog, a novel Bartonella sequence, and my father's death. Emerg Infect Dis 2009, 15(12):2080-2086.

20. Billeter SA, Caceres AG, Gonzales-Hidalgo J, Luna-Caypo D, Kosoy MY: Molecular detection of Bartonella species in ticks from Peru. J Med Entomol 2011, 48(6):1257-1260.

21. Billeter SA, Diniz PP, Battisti JM, Munderloh UG, Breitschwerdt EB, Levy MG: Infection and replication of Bartonella species within a tick cell line. Exp Appl Acarol 2009, 49(3):193-208.

22. Billeter SA, Kasten RW, Killmaster LF, Breitschwerdt EB, Levin ML, Levy MG, Kosoy MY, Chomel BB: Experimental infection by capillary tube feeding of Rhipicephalus sanguineus with Bartonella vinsonii subspecies berkhoffii. Comp Immunol Microbiol Infect Dis 2012, 35(1):9-15.

23. Cotte V, Bonnet S, Le Rhun D, Le Naour E, Chauvin A, Boulouis HJ, Lecuelle B, Lilin T, Vayssier-Taussat M: Transmission of Bartonella henselae by Ixodes ricinus. Emerg Infect Dis 2008, 14(7):1074-1080. 
24. Reis C, Cote M, Le Rhun D, Lecuelle B, Levin ML, Vayssier-Taussat M, Bonnet SI: Vector competence of the tick Ixodes ricinus for transmission of Bartonella birtlesii. PLoS Negl Trop Dis 2011, 5(5):e1186.

25. Breitschwerdt EB, Hegarty BC, Maggi R, Hawkins E, Dyer P: Bartonella species as a potential cause of epistaxis in dogs. J Clin Microbiol 2005, 43(5):2529-2533.

26. Riess T, Dietrich F, Schmidt KV, Kaiser PO, Schwarz H, Schafer A, Kempf VA: Analysis of a novel insect-cell culture medium-based growth medium for Bartonella species. Appl Environ Microbiol 2008, 74(16):5224-5227.

27. Bai Y, Kosoy MY, Boonmar S, Sawatwong P, Sangmaneedet S, Peruski LF: Enrichment culture and molecular identification of diverse Bartonella species in stray dogs. Vet Microbiol 2010, 146(3-4):314-319.

28. Kosoy M, Bai Y, Sheff K, Morway C, Baggett H, Maloney SA, Boonmar S, Bhengsri S, Dowell SF, Sitdhirasdr A, et al: Identification of Bartonella infections in febrile human patients from Thailand and their potential animal reservoirs. AmJTrop Med Hyg 2010, 82(6):1140-1145.

29. Herron MJ, Ericson ME, Kurtti TJ, Munderloh UG: The interactions of Anaplasma phagocytophilum, endothelial cells, and human neutrophils. Ann N Y Acad Sci 2005, 1063:374-382.

30. Wacnik PW, Baker CM, Herron MJ, Kren BT, Blazar BR, Wilcox GL, Hordinsky MK, Beitz AJ, Ericson ME: Tumor-induced mechanical hyperalgesia involves CGRP receptors and altered innervation and vascularization of DsRed2 fluorescent hindpaw tumors. Pain 2005, 115(1-2):95-106.

31. Sykes JE, Lindsay LL, Maggi RG, Breitschwerdt EB: Human coinfection with Bartonella henselae and two hemotropic mycoplasma variants resembling Mycoplasma ovis. J Clin Microbiol 2010, 48(10):3782-3785.

32. Pultorak E, Maggi RG, Mascarelli PE, Breitschwerdt EB: Serial testing from a three-day collection period using the BAPGM platform may enhance the sensitivity of Bartonella spp. detection in bacteremic human patients. J Clin Microbiol 2013. in press.

33. Pulliainen AT, Dehio C: Persistence of Bartonella spp. stealth pathogens: from subclinical infections to vasoproliferative tumor formation. FEMS Microbiol Rev 2012, 36(3):563-599.

34. Chomel BB: Cat-scratch disease. Rev Sci Tech 2000, 19(1):136-150

35. Ohl ME, Spach DH: Bartonella quintana and urban trench fever. Clin Infect Dis 2000, 31(1):131-135.

36. Smith DL: Cat-scratch disease and related clinical syndromes. Am Fam Physician 1997, 55(5):1783-1789. 1793-1784.

37. Kordick DL, Brown TT, Shin K, Breitschwerdt EB: Clinical and pathologic evaluation of chronic Bartonella henselae or Bartonella clarridgeiae infection in cats. J Clin Microbiol 1999, 37(5):1536-1547.

38. Kordick DL, Papich MG, Breitschwerdt EB: Efficacy of enrofloxacin or doxycycline for treatment of Bartonella henselae or Bartonella clarridgeiae infection in cats. Antimicrob Agents Chemother 1997, 41(11):2448-2455.

39. Schulein R, Seubert A, Gille C, Lanz C, Hansmann Y, Piemont Y, Dehio C: Invasion and persistent intracellular colonization of erythrocytes. A unique parasitic strategy of the emerging pathogen Bartonella. J Exp Med 2001, 193(9):1077-1086.

40. Seubert A, Schulein R, Dehio C: Bacterial persistence within erythrocytes: a unique pathogenic strategy of Bartonella spp. Int J Med Microbiol 2002 291(6-7):555-560.

41. Schaller JL: Bartonella: Diagnosis and treatment - A major cause of lyme disease complications and psychiatric problems, Volume 1. Hope Academic Press; 2008:250. ISBN 10: 0979925088.

42. Kohlstadt I: Advancing medicine with food and nutrients, Volume 1. 2nd edition. NY: CRC Press; 2012.

43. Kerkhoff FT, Bergmans AM, van Der Zee A, Rothova A: Demonstration of Bartonella grahamii DNA in ocular fluids of a patient with neuroretinitis. J Clin Microbiol 1999, 37(12):4034-4038.

44. Rothova A, Kerkhoff F, Hooft HJ, Ossewaarde JM: Bartonella serology for patients with intraocular inflammatory disease. Retina 1998, 18(4):348-355

45. Bergmans AM, de Jong CM, van Amerongen G, Schot CS, Schouls LM: Prevalence of Bartonella species in domestic cats in The Netherlands. J Clin Microbiol 1997, 35(9):2256-2261.

46. Tijsse-Klasen E, Fonville M, Gassner F, Nijhof AM, Hovius EK, Jongejan F, Takken W, Reimerink JR, Overgaauw PA, Sprong H: Absence of zoonotic Bartonella species in questing ticks: first detection of Bartonella clarridgeiae and Rickettsia felis in cat fleas in the Netherlands. Parasit Vectors 2011, 4:61.
47. Pinna A, Puglia E, Dore S: Unusual retinal manifestations of cat scratch disease. Int Ophthalmol 2011, 31(2):125-128.

48. Vermeulen MJ, Herremans M, Verbakel H, Bergmans AM, Roord JJ, van Dijken PJ, Peeters MF: Serological testing for Bartonella henselae infections in The Netherlands: clinical evaluation of immunofluorescence assay and ELISA. Clin Microbiol Infect 2007, 13(6):627-634.

49. Kordick DL, Breitschwerdt EB: Relapsing bacteremia after blood transmission of Bartonella henselae to cats. Am J Vet Res 1997, 58(5):492-497.

50. Diniz PP, Maggi RG, Schwartz DS, Cadenas MB, Bradley JM, Hegarty B, Breitschwerdt EB: Canine bartonellosis: serological and molecular prevalence in Brazil and evidence of co-infection with Bartonella henselae and Bartonella vinsonii subsp. berkhoffii. Vet Res 2007, 38(5):697-710.

51. Diniz PP, Wood M, Maggi RG, Sontakke S, Stepnik M, Breitschwerdt EB: Co-isolation of Bartonella henselae and Bartonella vinsonii subsp. berkhoffii from blood, joint and subcutaneous seroma fluids from two naturally infected dogs. Vet Microbiol 2009, 138(3-4):368-372.

52. Duncan AW, Marr HS, Birkenheuer AJ, Maggi RG, Williams LE, Correa MT, Breitschwerdt EB: Bartonella DNA in the blood and lymph nodes of Golden Retrievers with lymphoma and in healthy controls. J Vet Intern Med 2008, 22(1):89-95.

53. Morales SC, Breitschwerdt EB, Washabau RJ, Matise I, Maggi RG, Duncan AW: Detection of Bartonella henselae DNA in two dogs with pyogranulomatous lymphadenitis. J Am Vet Med Assoc 2007 230(5):681-685.

54. Perez C, Maggi RG, Diniz PP, Breitschwerdt EB: Molecular and serological diagnosis of Bartonella infection in 61 dogs from the United States. J Vet Intern Med 2011, 25(4):805-810.

55. Harms C, Maggi RG, Breitschwerdt EB, Clemons-Chevis CL, Solangi M, Rotstein DS, Fair PA, Hansen LJ, Hohn AA, Lovewell GN, et al: Bartonella species detection in captive, stranded and free-ranging cetaceans. Vet Res 2008, 39(6):59.

56. Maggi RG, Harms CA, Hohn AA, Pabst DA, McLellan WA, Walton WJ, Rotstein DS, Breitschwerdt EB: Bartonella henselae in porpoise blood. Emerg Infect Dis 2005, 11(12):1894-1898.

57. Beard AW, Maggi RG, Kennedy-Stoskopf S, Cherry NA, Sandfoss MR, DePerno CS, Breitschwerdt EB: Bartonella spp. in feral pigs, southeastern United States. Emerg Infect Dis 2011, 17(5):893-895.

58. Cherry NA, Jones SL, Maggi RG, Davis $U$, Breitschwerdt EB: Bartonella spp. infection in healthy and sick horses and foals from the Southeastern United States. J Vet Intern Med 2012, 26(6):1408-1412.

59. Johnson R, Ramos-Vara J, Vemulapalli R: Identification of Bartonella henselae in an aborted equine fetus. Vet Pathol 2009, 46(2):277-281.

60. Jones SL, Maggi R, Shuler J, Alward A, Breitschwerdt EB: Detection of Bartonella henselae in the blood of 2 adult horses. J Vet Intern Med 2008, 22(2):495-498

61. Maggi RG, Raverty SA, Lester SJ, Huff DG, Haulena M, Ford SL, Nielsen O, Robinson JH, Breitschwerdt EB: Bartonella henselae in captive and hunterharvested beluga (Delphinapterus leucas). J Wildl Dis 2008, 44(4):871-877.

62. Breitschwerdt EB, Maggi RG, Nicholson WL, Cherry NA, Woods CW Bartonella sp. bacteremia in patients with neurological and neurocognitive dysfunction. J Clin Microbiol 2008, 46(9):2856-2861.

63. Bouchouicha R, Durand B, Monteil M, Chomel BB, Berrich M, Arvand M, Birtles RJ, Breitschwerdt EB, Koehler JE, Maggi R, et al: Molecular epidemiology of feline and human Bartonella henselae isolates. Emerg Infect Dis 2009, 15(5):813-816.

64. Boulouis HJ, Chang CC, Henn JB, Kasten RW, Chomel BB: Factors associated with the rapid emergence of zoonotic Bartonella infections. Vet Res 2005, 36(3):383-410

65. Mietze A, Strube C, Beyerbach M, Schnieder T, Goethe R: Occurrence of Bartonella henselae and Borrelia burgdorferi sensu lato co-infections in ticks collected from humans in Germany. Clin Microbiol Infect 2011, 17(6):918-920.

66. Stanek G: Pandora's Box: pathogens in Ixodes ricinus ticks in Central Europe. Wien Klin Wochenschr 2009, 121(21-22):673-683.

67. Podsiadly E, Chmielewski T, Marczak R, Sochon E, Tylewska-Wierzbanowska S: Bartonella henselae in the human environment in Poland. Scand J Infect Dis 2007, 39(11-12):956-962.

68. Podsiadly E, Chmielewski T, Sochon E, Tylewska-Wierzbanowska S: Bartonella henselae in Ixodes ricinus ticks removed from dogs. Vector Borne Zoonotic Dis 2007, 7(2):189-192. 
69. Sanogo YO, Zeaiter Z, Caruso G, Merola F, Shpynov S, Brouqui P, Raoult D: Bartonella henselae in Ixodes ricinus ticks (Acari: Ixodida) removed from humans, Belluno province. Italy. Emerg Infect Dis 2003, 9(3):329-332.

70. Bonnet S, de la Fuente J, Nicollet P, Liu X, Madani N, Blanchard B, Maingourd C, Alongi A, Torina A, de Mera IG F, Vincente J, George JC, Vayssier-Taussat $\mathrm{M}$, Joncour $\mathrm{G}$ : Prevalence of tick-borne pathogens in adult Dermacentor spp. ticks from nine collection sites in France. Vector Borne Zoonotic Dis 2013 [Epub ahead of print].

71. Corrain R, Drigo M, Fenati M, Menandro ML, Mondin A, Pasotto D, Martini M: Study on ticks and tick-borne zoonoses in public parks in Italy. Zoonoses Public Health 2012, 59(7):468-476.

72. Cotte V, Bonnet S, Cote M, Vayssier-Taussat M: Prevalence of five pathogenic agents in questing Ixodes ricinus ticks from western France. Vector Borne Zoonotic Dis 2010, 10(8):723-730.

73. Dietrich F, Schmidgen T, Maggi RG, Richter D, Matuschka FR, Vonthein R Breitschwerdt EB, Kempf VA: Prevalence of Bartonella henselae and Borrelia burgdorferi sensu lato DNA in Ixodes ricinus ticks in Europe. Appl Environ Microbiol 2010, 76(5):1395-1398.

74. Reye AL, Hubschen JM, Sausy A, Muller CP: Prevalence and seasonality of tick-borne pathogens in questing Ixodes ricinus ticks from Luxembourg Appl Environ Microbiol 2010, 76(9):2923-2931.

75. Reye AL, Stegniy V, Mishaeva NP, Velhin S, Hubschen JM, Ignatyev G, Muller CP: Prevalence of tick-borne pathogens in Ixodes ricinus and dermacentor reticulatus ticks from different geographical locations in Belarus. PLoS One 2013, 8(1):e54476.

76. Sytykiewicz H, Karbowiak G, Werszko J, Czerniewicz P, Sprawka I, Mitrus J: Molecular screening for Bartonella henselae and Borrelia burgdorferi sensu lato co-existence within Ixodes ricinus populations in central and eastern parts of Poland. Ann Agric Environ Med 2012, 19(3):451-456.

77. Schouls LM, Van De Pol I, Rijpkema SG, Schot CS: Detection and identification of Ehrlichia, Borrelia burgdorferi sensu lato, and Bartonella species in Dutch Ixodes ricinus ticks. J Clin Microbiol 1999, 37(7):2215-2222.

78. Chondrogiannis K, Vezakis A, Derpapas M, Melemeni A, Fragulidis G: Seronegative cat-scratch disease diagnosed by PCR detection of Bartonella henselae DNA in lymph node samples. Braz I Infect Dis 2012, 16(1):96-99.

79. Lin YY, Hsiao CH, Hsu YH, Lee CC, Tsai HJ, Pan MJ: Immunohistochemical study of lymph nodes in patients with cat scratch disease. J Formos Med Assoc 2006, 105(11):911-917.

doi:10.1186/1756-3305-6-101

Cite this article as: Maggi et al:: Bartonella henselae bacteremia in a mother and son potentially associated with tick exposure. Parasites \& Vectors 2013 6:101

\section{Submit your next manuscript to BioMed Central and take full advantage of:}

- Convenient online submission

- Thorough peer review

- No space constraints or color figure charges

- Immediate publication on acceptance

- Inclusion in PubMed, CAS, Scopus and Google Scholar

- Research which is freely available for redistribution 